\title{
LA RUTA ESCULTÓRICA DEL AGERO Y EL CEMENTO DE LA CIUDAD DE MONTERREY, UN PATRIMONIO CULTURAL ARTÍSTICO
}

POR REVALORAR

\section{THE SCULPTURE ROUTE OF STEEL AND GEMENT OF MONTERREY CITY, AN ARTISTIC CULTURAL HERITAGE TO BE REVALUED.}

\section{GUADALUPE MAURICIO HERNÁNDEZ}

Maestra de tiempo completo en UANL.

Escuela Industrial y Preparatoria

Técnica Pablo Livas.

Universidad Autónoma de Nuevo León

Jiménez 321, Sur. Centro de Monterrey, (México) CP: 64000

Tlfn: + 8180745954

Email: lupitamhdz@hotmail.com

guadalupemazapil@gmail.com

PALABRAS CLAVES

Escultura urbana, Nuevo espacio público visual, Arte público, Mirada, Ciudad del Futuro.
KEY WORDS

Urban sculpture, New Public Space, Public Art, Glance, City of the Future. 


\section{Resumen}

En 2007, la ciudad de Monterrey experimentó uno de los proyectos de Arte Público más ambicioso e importante en su historia: formar una ruta escultórica a lo largo del río Santa Catarina, y para ello se convocó a prestigiados artistas internacionales como Albert Paley, Óscar Niemeyer, Bruce Beasley, Mathías Goeritz, Josep María Sirvent, Julio Le Parc, Jorge Elizondo, Ahmed Nawar, para que donaran una escultura. Esta experiencia representó retos para los artistas, dada la particular instalación como obras monumentales en las orillas de un río seco que divide a la ciudad en su centro. Las esculturas fueron colocadas ahí para ser vistas desde lejos y a velocidad, es decir, desde un automóvil que recorre la avenida, y a una distancia que ofrece la posibilidad de ser miradas como parte del paisaje urbano. Aparte de esto, la ruta como marca en el espacio, ofrece indicadores sobre la ciudad del futuro y el nuevo espacio público, simbólicamente trazado con las esculturas. Sin embargo, a pesar del valor artístico que tienen las ocho esculturas, sufren de abandono y mantenimiento a partir del huracán Alex en julio de 2010. "La Ruta Escultórica del Acero y el Cemento" (REAC) representa un antecedente que debe revisarse, como modelo basado en el arte público, para impactar la ciudad.

\section{Abstract}

In 2007, Monterrey city experienced one of the most ambitious and important public art projects in its history: to form a sculptural route along the Santa Catarina River, and for this it was attracted prestigious international artists such as Albert Paley, Óscar Niemeyer, Bruce Beasley, Mathias Goeritz, Josep María Sirvent, Julio Le Parc, Jorge Elizondo, Ahmed Nawar, to donate a sculpture. This experience represented challenges to the artists, given the particular installation as monumental works on the slopes of a dry river that divides the city in its center. The sculptures were placed there to be seen from afar and at speed, that is, from a car that runs along the avenue, and at a distance that offers the possibility of being looked at as part of the urban landscape. Besides, the route, as a mark in space, offers indicators on the city of the future and the new public space, symbolically drawn with the sculptures. However, despite the artistic value of the eight sculptures, they suffer from abandonment and lack of maintenance after Hurricane Alex in July 2010. "The Sculpture Route of Steel and Cement" (REAC) represents a precedent that must be reviewed, as Model based on public art, to impact the city. 


\section{Introducción}

El tema de este trabajo trata sobre la mutación del espacio público a partir del arte púbico que nos evidencia el caso empírico de la Ruta Escultórica del Acero y el Cemento en Monterrey (en adelante REAC). Partimos de la idea de que el arte puede ser un indicador valido para entender los nuevos espacios urbanos; un propósito es la de evitar la tentación de subordinar el arte público posmoderno, principalmente de las obras arquitectónicas, la escultura monumental, a los intereses del poder económico y la economía global, perdiendo de vista la propuesta estética de la obra artística. El caso que se estudia es la construcción de una ruta escultórica integrada por piezas monumentales de prestigiados artistas internacionales a lo largo del rio Santa Catarina, un río seco que divide el centro de la ciudad y cruza por tres de los principales municipios del Área Metropolitana de Monterrey. Llama la atención en este caso que se trata del segundo intento por marcar el área del río Santa Catarina con esculturas monumentales; el primero, se podría considerar un proyecto inacabado que data de 1979. La insistencia de ambos proyectos en ubicarse en el mismo sitio, pese a que el río se ha desbordado en varias ocasiones con las fuertes lluvias provocadas por huracanes, nos llevó a reflexionar sobre el significado de la construcción de estos proyectos, más allá de una mera intención de embellecer la ciudad y a preguntarnos sobre el espacio público, la ciudad y su relación con el arte.

El supuesto que se considera es la necesidad de una élite industrial y clase política local por etiquetar o refundar ese espacio de la ciudad invisible, o futura ciudad posmoderna, con un relato ideológico, donde la élite empresarial local trata de hacerse presente y que se identifique la grandeza de Monterrey con dicha élite; no obstante, esta etiqueta, del acero y el cemento como mercancías generadoras de la riqueza de Monterrey, dificulta la comprensión estética del proyecto, y de la escultura como objeto artístico de estudio e indicador de los nuevos fenómenos urbanos. Los conceptos importantes en este trabajo son la ciudad y el espacio público; por otra parte, el arte público posmoderno y la mirada, así como el seguimiento histórico del desarrollo de la REAC.

\section{Objetivos}

\section{General:}

Entender la relación del arte público y la creación de un nuevo espacio urbano visual en el contexto de la globalización en la época posmoderna.

\section{Particulares:}

Ensayar elementos de análisis sobre los nuevos fenómenos urbanos en la ciudad de Monterrey desde los estudios visuales. 


\section{Metodología}

La investigación se desarrolla a partir de un análisis interdisciplinario desde el urbanismo y los estudios visuales y se concreta como un estudio de caso sobre "La Ruta Escultórica del Acero y el Cemento" (REAC), esculturas monumentales, que se encuentran en los bordes del río Santa Catarina. Tiene como antecedente una revisión del arte público de la década de los ochenta y principios de los noventa en Monterrey, donde la obra artística en la vía pública empieza a ser protagonista de la llamada época posmoderna, esto llevó a relacionar el fenómeno del arte público con el surgimiento de un nuevo espacio público urbano visual. El marco de referencias teóricas de lo urbano se apoya en autores que versan sobre el concepto de espacio público y la ciudad; en las referencias teóricas de lo visual en conceptos como arte público posmoderno y la mirada como herramienta de análisis de los fenómenos de las artes visuales. Las fuentes de información fueron entrevistas, revisión bibliográfica, hemerográfica; registro fotográfico, observación de campo. Así también se elaboran dos tablas comparativas: 1) sobre las principales características del espacio público moderno y del espacio público posmoderno; 2) sobre los aspectos del primer proyecto escultórico urbano en el río Santa Catarina y de la REAC. La investigación incorpora un trabajo fotográfico de campo sobre cada una de las 8 esculturas de la Ruta, lo que constituye un apoyo importante para el análisis.

\section{La ciudad y espacio público urbano}

La ciudad es históricamente, para Borja y Muxi (2003), el "producto cultural" más "complejo y significante" de la historia de la humanidad (p. 30). Esto obedece al hecho de que maximiza "las posibilidades de intercambio" diverso (p.30). Si en la sociedad moderna capitalista la industria influía de una manera determinante en la organización y designación de los espacios de la ciudad; en la posmodernidad esta capacidad infinita de intercambio propio de las ciudades renace en el interés de generar espacios públicos urbanos relacionados al arte público y al entretenimiento.

Delgado (2007), plantea que el "espacio urbano", es una modalidad singular del espacio social "escenario y producto de lo colectivo", "relaciones diagramáticas entre objetos bucles, nexo sometidos a un estado de excitación permanente y hechos de simultaneidad y confluencia", "un determinado sistema de relaciones sociales" que nacen como una "proliferación de marañas relacionales, compuestas de usos, componendas, impostaciones, rectificaciones, y adecuaciones mutuas que van emergiendo a cada momento" (p. 12).

Cabe aquí plantear con Delgado lo que no es el espacio urbano: no es un espacio planificado o predispuesto, con un uso y un horario determinado. El espacio urbano, al que se refiere Delgado (2007), parte de una "dialéctica ininterrumpidamente renovada y auto administrada de miradas y exposiciones" ( $p$. 14). Es un espacio efímero, heterogéneo, de interacción superficial, pero es el espacio donde individuos y grupos "definen y estructuran" sus relaciones con el poder, ya sea para someterse o subordinarse o para ignorarlo. Este espacio es emergente, radical y no puede "patrimonializarse como cosa" (p. 12). Aunque el poder intente domesticarlo "a través de innumerables medios e instrumentos políticos, sociales, policiacos y 
arquitectónicos", "no es un lugar, sino un tener lugar de los cuerpos que lo ocupan en extensión y en tiempo" (p. 13). No es tampoco la suma, sino la relación de diversas individualidades como se constituye el espacio urbano, espacio percibido, vivido, usado.

Retomamos de Delgado la característica del espacio urbano como un espacio autoadministrado de miradas y distinguimos de su concepto de espacio urbano: "la simultaneidad y la confluencia" (Delgado, 2007, p.12) que le otorgan al espacio la cualidad de existir en el momento y en el lugar en que acontece en la acción o "experiencia masiva",

En este trabajo se formula la existencia de un nuevo espacio urbano, de carácter visual, no es colectivo en su origen y surge a través de la relación de diversas individualidades que confluyen, cada una por su cuenta, en un punto visual a partir de la mirada. Se busca la interacción, la interferencia, pero no la confluencia simultánea, si bien son las miradas las que confluyen, no hay un suceso por el cual se reúnan, ni son acontecimiento; lo que las hace confluir es cruzar cotidianamente el mismo espacio.

El concepto de nuevo espacio público urbano que aquí se propone en su relación con el arte y creado por el arte, no posee el acto de la simultaneidad mencionado por Delgado, pero sí está presente la confluencia. Por tal razón se dice que tal espacio es un nuevo espacio público urbano.

En el estudio de la ciudad posmoderna, Amendola (2000), aporta dos conceptos para el análisis de la "nueva sociedad"; se trata de una distinción dual que permite analizar la ciudad posmoderna en dos planos: el cityscape que se refiere al "panorama físico de la ciudad" y el mindscape como el "panorama del alma y de las culturas". Señala que el mindscape "cambia mucho más rápidamente que el edificio construido de la ciudad" (p. 16). La nueva ciudad de la que habla Amendola (2000), es decir, la ciudad posmoderna, se asemeja a una ciudad invisible, al menos materialmente hablando, pero que es perceptible como imagen o imaginario, "de manera fragmentada, lacerada a través de los sueños, los miedos, los gustos y los consumos de la gente" (p. 17), es decir "en las culturas, los valores, en los estilos de vida", fuertemente influidos por el consumo. El espacio que genera La Ruta Escultórica del Acero y el Cemento aparecen como las marcas de un trazado de la futura ciudad posmoderna, una "ciudad invisible", que todavía no existe, pero que nos indica que será ahí, a lo largo de las orillas del río Santa Catarina, uno de sus centros, un in y un out que redefine el territorio de la ciudad y su conexión con las distintas zonas del Área Metropolitana de Monterrey.

El planteamiento que hace Castells (2008), desde una perspectiva sociológica marxista, dice que para entender la urbanización "se debe partir de la relación entre fuerzas productivas, clases sociales y formas culturales (el espacio entre ellas)" (p. 14), es pertinente por dos razones: la primera, señalada por Castells, es que resulta insuficiente explicar los fenómenos urbanos a través de la mera contextualización ( $p$. 14); la segunda es superar la tentación de reducir las formas culturales a intereses políticos o económicos, muchas veces coyunturales, sin considerar las mediaciones, mencionadas por Castells. La relación del arte posmoderno, principalmente de las obras arquitectónicas, la escultura monumental y cierto tipo de publicidad, con el poder económico y la economía global, no se esclarece con el hecho de decir que el arte posmoderno 
sirve a los intereses de la economía mundo, o que enmascara la realización de los grandes negocios, o que el arte sirve solamente de decoración en el escenario donde se realizan los negocios de las trasnacionales.

\section{Arte público posmoderno}

Grau (2007), señala que en la era de la posmodernidad destaca el resurgimiento del arte público, el cual convierte al espacio público de las ciudades "en el principal campo de actuación de los artistas”; así mismo, señala que "Durante la década de los años 80, en plena posmodernidad, se produce la recuperación y consolidación del arte público, una práctica artística surgida a lo largo del siglo XIX que había perdido fuerza en la época de las vanguardias".

A la vez que el arte ocupa el espacio urbano, los museos entran en una crisis, donde se debate su función tradicional. En la medida que el público se va convirtiendo en un espectador cada vez con mayor participación en una nueva ciudad en la cual el arte forma parte de un espectáculo.

Dos son los factores que en este trabajo se consideran fundamentales para el resurgimiento del arte público en la actualidad: el primer factor tiene que ver con la fuerte tendencia de los artistas, en la posmodernidad, a realizar sus obras como arte público, hacerla parte de la ciudad, lo cual tiene como consecuencia que sea convertida en evento e involucre a un número considerable de ciudadanos. Amendola (2000) enfatiza el hecho de que la obra de arte se valore y juzgue tomando en cuenta "el efecto artístico sobre el espacio y la intensidad de la relación entre el objeto artístico y la gente" (p. 141). El autor señala también que el juicio subjetivo de la gente, de esta forma, prevalece por sobre el juicio de "los actores tradicionalmente legitimados para formularlos" (p. 142). El hecho señalado define uno de los rasgos más importantes del arte posmoderno: la interacción con la gente, lo cual impulsa a los artistas a buscar el espacio público, es decir, se busca la reacción, la interacción, irrumpiendo en la vía pública, interceptando la mirada de los transeúntes.

\begin{tabular}{|l|l|}
\hline \multicolumn{2}{|c|}{ Cambios en el Espacio público urbano } \\
\hline $\begin{array}{l}\text { Espacio público moderno tradi- } \\
\text { cional }\end{array}$ & Espacio público posmoderno \\
\hline Punto de reunión colectiva & Experiencia individual \\
\hline Arte figurativo & Arte abstracto/efímero/otros \\
\hline Interacción física & Interacción visual \\
\hline Función ideológica-política & Función estética-cultural \\
\hline Espacio planeado & Espacio abierto \\
\hline Mirada dirigida & Mirada abierta \\
\hline Distancia corta & Distancia lejana \\
\hline Espacio físico & Espacio visual \\
\hline Movimiento & Velocidad \\
\hline
\end{tabular}

Tabla 1. Elaborada por Guadalupe Mauricio Hernández (2016). 
El segundo factor vinculado al resurgimiento del arte público está expresado por el Manifiesto que emite la Cumbre Mundial de las Artes (World Arts Summit), celebrada en Venecia en 1991, patrocinada por el Foro Económico Mundial, cuya sede es Davos, Suiza, conocido como Grupo de Davos: "El arte, dice el manifiesto, para una sociedad global [...] es la lengua de la cultura, forma única de expresión creativa que nos permite comunicar y construir puentes realmente de dimensiones mundiales" (Debray, 1994, p. 210).

Es visible que los poderosos hombres de negocios, representados en Davos, se interesan por los "puentes" de "dimensiones globales", sobre todo en un mundo globalizado, cuya economía trasnacional enfrenta conflictos armados, políticos, sociales, culturales, religiosos, étnicos, muchos de ellos también de dimensiones globales. El arte parece ser para los hombres de negocios, el elemento ideal que sirve de marco (imagen) para las inversiones. Y es el arte público posmoderno el que mejor cumple la función de "puente", en la medida que se considera lenguaje universal que busca interactuar con la gente.

La estetización de la vida cotidiana, Amendola, (2000, p. 148) y Brea (1996, p. 19), se ha convertido en uno de los efectos más notables de arte público posmoderno. Sin embargo, el encuentro entre el arte y el habitante de la ciudad posmoderna está mediado por el espectáculo, el evento, el acontecimiento mediático. El arte posmoderno pasa a ser una parte fundamental de dicho espectáculo de masas (Brea, 1996, p. 19 y Amendola, 2000, p. 158).

\section{Aproximaciones para el análisis de la mirada}

\subsection{La imagen y la mirada}

En la era de lo visual, la imagen adquiere una relevancia primordial, según sostiene Debray (1994). También la tiene "la mirada" que ponemos en las cosas que representan otras cosas. Finalmente, lo que vemos no son solamente cosas, sino relaciones entre personas y las cosas. Debray emprendió hace dos décadas la tarea de plasmar la historia de la mirada en Occidente, trabajo complejo en la medida que la mirada tiene que ver con la historia de la religión y se vincula estrechamente con la historia de arte, y luego con la tecnología. En nuestra era, reina la imagen, entrelazada con el consumo hedonista del individualismo. En la era de la "videosfera", como nos muestra Debray, la imagen se tiene como referencia a sí misma, lo cual implica la posibilidad de que se convierta en referencia dominante de lo real y, en cierto sentido, tome el lugar de la realidad; y todo esto sucede en y por la mirada. Una imagen es capaz de producir reacciones más poderosas que mil palabras, por ello no es de extrañar pues que en la era que posibilita la reproducción y difusión técnica masiva de la imagen, la era de la economía global capitalista, su productividad se vincule al consumo y a la legitimidad del poder. La imagen en esta sociedad también es susceptible de convertirse en una mercancía. De hecho, sólo el arte había logrado, o intentado, crear su propio reino autónomo que, por decirlo así, "escapara", hasta cierto punto, de las condiciones o determinantes históricas, e incluso trascendiera el tiempo, las diferentes culturas y lenguas. Centrar el análisis del arte público y el espacio urbano en la mirada, posibilita mostrar la relación que se establece entre el arte público vinculado a un espacio urbano determinado y la relación que se entabla entre la obra de arte y quien la mira. Retomamos el planteamiento de Berger 
(2010) donde plantea que toda imagen encarna un modo de ver, y que miramos no solamente una cosa aislada, sino las relaciones entre las cosas.

\subsection{La mirada}

El nuevo espacio vinculado al arte posmoderno tiende, potencialmente, a generar imágenes, de donde surge la idea de que la ciudad está constituida de miradas y un posible análisis de la mirada para el presente trabajo: La mirada distraída, mirada concentrada, mirada domesticada, mirada panorámica, mirada del coleccionista, mirada turística, mirada dirigida, la mirada abierta.

Miramos relaciones culturales, políticas, económicas, estéticas, al mirar el arte público. Estas obras no solamente están ahí, sino que están de una manera para ser vistas y el espacio urbano donde están no es un simple escenario neutro, sino que es parte fundamental de las relaciones que encuentran su significado en la mirada.

Miramos el arte público posmoderno con una Mirada Distraída, aquella que no encuentra las referencias básicas, no reconoce a qué se parece, no sabe para qué sirve, ni qué está haciendo ahí; para la mirada distraída no hay relaciones, sólo cosas aisladas. Está vinculada a la visión periférica, la cual juega un rol importante, al respecto Juhani Pallasmaa (2006), nos dice: "La percepción periférica inconsciente transforma la Gestalt retiniana en experiencias espaciales y corporales. La visión periférica nos integra en el espacio, mientras que la visión enfocada nos expulsa de él convirtiéndonos en meros espectadores" (p. 13). Se mira también con una Mirada Panorámica que reconoce al arte público como un objeto que pertenece a una imagen panorámica de la ciudad, plasmada en postales e imágenes publicitarias que representan a la ciudad. Esta mirada panorámica está vinculada a la Mirada Turística que ve a la ciudad como un enorme parque de diversiones, donde el arte público representa lo bello, lo agradable, lo decorativo, y en ocasiones lo raro. La Mirada Turística se desplaza por la diversión, el esparcimiento, en el menor tiempo posible, pero busca el espectáculo, la magia, la experiencia breve, que le indique una aventura única especial. Otra mirada posible es la Mirada Concentrada, la del experto en historia del arte, poseedor de conocimientos especializados: mirada que todo lo reduce a un valor estético autónomo. La mirada que conlleva preguntas, dudas, que mira la mirada, que a su vez lo mira, es una Mirada Abierta a los múltiples significados, estéticos, culturales, sociales, que el arte público ofrece.

Brea (2005), señala la importancia de los actos de ver en la construcción cultural y, por ende, en el análisis visual de las obras artísticas. Ver implica para Brea un complejo acto que capta diversos elementos como son los textuales, imaginarios, técnicos, sensoriales, mediáticos, técnicos, burocráticos institucionales (p.8 y 9 ). 


\section{La Ruta Escultórica del Acero y el Cemento (REAC)}

La Ruta Escultórica del Acero y el Cemento fue Inaugurada el 18 de septiembre de 2009, durante la administración del gobernador José Natividad González Parás. Estuvo diseñada como parte del programa de regeneración urbana para el Fórum Universal de las Culturas Monterrey 2007. Originalmente, según Pérez (2007), fue nombrada Ruta del Acero, Vidrio y Cemento. El proyecto fue concesionado en mayo de 2005 al escultor chihuahuense Enrique Carbajal "Sebastián" mediante un convenio de colaboración entre la Agencia Para el Desarrollo Urbano de Nuevo León (ADUNL) y el escultor. A este proyecto se sumó la formación de un comité ciudadano integrado por especialistas arquitectos, ingenieros y reconocidos promotores culturales que, en conjunto con la ADUNL, sustentaron el proyecto de la REAC.

La idea de realizar una ruta de esculturas (corredor escultórico) en las orillas del río Santa Catarina, data de 1979, bajo una idea planteada por la familia de empresarios Fernández Garza. Este corredor estaría formado por 22 monumentos de 15 metros de altura a instalarse en un "bulevar" de 22 kilómetros en la ciudad. Solo se logró la construcción de las esculturas de Rafael Calzada, (patrocinada por la empresa Cerámica Regiomontana), Manuel Felguérez (patrocinada por Cydsa), Rufino Tamayo (patrocinada por ALFA). En ese primer proyecto se pretendía, según Guillermo Sepúlveda, promotor cultural, (entrevistado por Ortiz, 2009), "una especie de museo al aire libre en el que se pudieran ver [esculturas] a grandes distancias y a grandes velocidades" (p. 88).

\begin{tabular}{|l|l|}
\hline \multicolumn{1}{|c|}{ Corredor escultórico 1979 } & \multicolumn{1}{c|}{ Ruta escultórica del acero y el cemento } \\
\hline Idea e iniciativa del Sector Privado & Idea e iniciativa del Sector público \\
\hline Financiamiento del sector privado & Financiamiento sector público \\
\hline Mejorar la imagen urbana & Plan de Regeneración urbana \\
\hline Espacio público & Espacio público \\
\hline $\begin{array}{l}\text { Reivindicar la imagen del empresario } \\
\text { Roberto Garza y embellecer la ciudad }\end{array}$ & $\begin{array}{l}\text { Reivindicar la imagen del gobernador Natividad } \\
\text { González Parás y crear la "marca ciudad" }\end{array}$ \\
\hline Vistas a velocidad y distancia & Vistas a velocidad y distancia \\
\hline 15 metros de altura promedio & 20 metros de altura promedio \\
\hline 22 esculturas & 8 esculturas \\
\hline 22 kilómetros & 7.5 Kilómetros \\
\hline Materiales diversos & Acero y cemento \\
\hline Artistas nacionales & Artistas internacionales \\
\hline Bulevar & Parque lineal \\
\hline Se construyeron tres esculturas & Se construyeron ocho esculturas \\
\hline Comité empresarial y cultural & $\begin{array}{l}\text { Comité institucional y de especialistas } \\
\text { ciudadanos }\end{array}$ \\
\hline
\end{tabular}

Tabla 2. Elaborada por Guadalupe Mauricio Hernández (2016). 
Para crear la REAC convocaron a una serie de artistas escultores internacionales y locales, finalmente quedó conformada por un conjunto de esculturas monumentales de prestigiados escultores internacionales y la obra de un artista local, seleccionada mediante un concurso, donde estuvieron invitados, según Pérez (2007), otros escultores locales. Las piezas quedaron instaladas en su mayoría en el desparecido Parque Lineal, del río Santa Catarina (7.5 Kilómetros), con excepción de la obra de Mathías Goeritz, ubicada en un montículo en el paseo Santa Lucía, vista desde la avenida Constitución.

Las esculturas que forman la Ruta Escultórica del Acero y el Cemento son: Luna, de Óscar Niemeyer (Brasil); Desafío, de Ahmed Nawar (Egipto); Evanescencia, de Albert Paley (Estados Unidos); Destino, de Bruce Beasley (Estados Unidos); Nube, de Jorge Elizondo (México, NL); Mirada, de Josep María Sirvent (España); y Torsión 4, de Julio Le Parc (Argentina); Serpiente del Eco 1, de Mathías Goeritz

La ubicación para cada escultura de la REAC quedó acordada por los escultores, pues a ellos se les dio la libertad de elegir el lugar y prever el ángulo visual de las miradas, tomando en cuenta el Parque lineal y el sentido de las avenidas a ambos lados del río Santa Catarina, según se puede inferir por entrevistas realizadas a los escultores. Aunque, es obvio, que se consideró el paisaje y ciertos lugares simbólicos de Monterrey como las montañas, el Parque Fundidora o la Macroplaza.

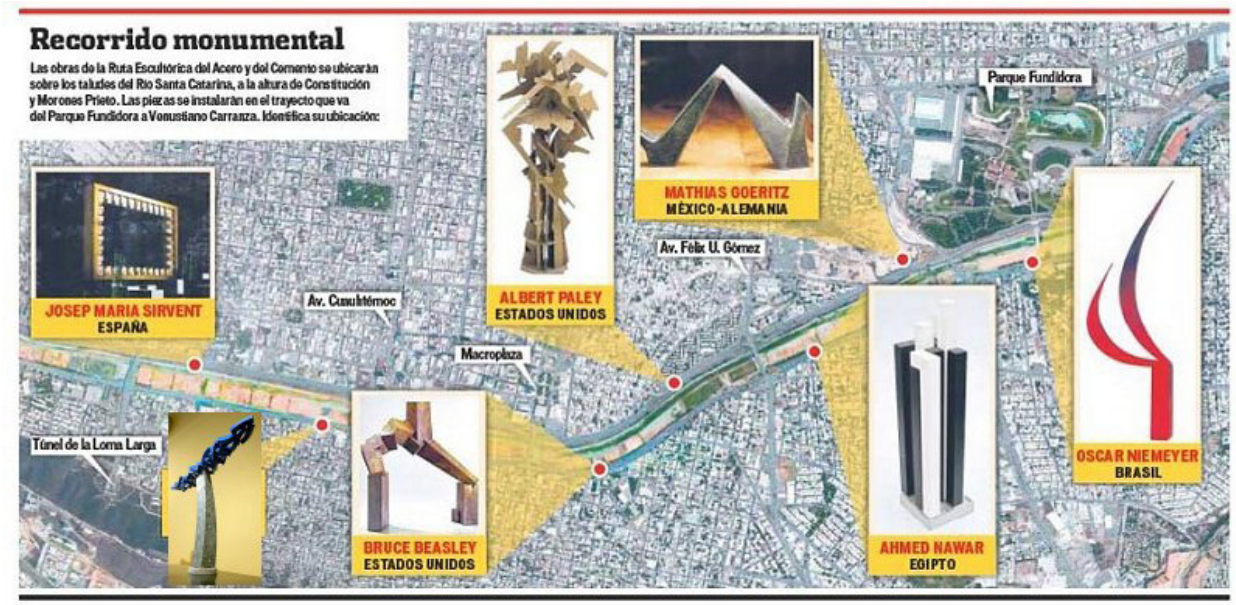

Mapa de La Ruta del Acero y el Cemento.

Imagen tomada de http://culturacolectiva.com/la-ruta-escultorica-acero-y-cemento-en-monterrey/

\section{Los artistas, la obra, el paisaje y la mirada}

Las esculturas de la REAC al lado del río Santa Catarina, fueron colocadas ahí para ser vistas desde un automóvil que recorre la avenida, y a una distancia que ofrece la posibilidad de ser miradas como parte del paisaje urbano. Dichas esculturas carecen de espacio a su alrededor como sucede con las esculturas montadas en la plaza pública tradicional; las esculturas de la REAC están hechas sólo para ser miradas individualmente a cierta distancia y sólo por los instantes que permita el tráfico. La mirada de los automovilistas o de los pasajeros de los camiones urbanos, no encontrarán asidero alguno, serán miradas breves, distraídas, individuales; miradas que incluso no alcanzarán a ver, reconocer, a anclar en la memoria. Las esculturas 
emergen en el paisaje urbano como una señal, una marca. Esta forma particular de apreciación de las esculturas representó uno de los retos más importantes para cada uno de los escultores vivos.

Como ejemplo abordamos dos casos: la pieza Mirada del escultor español autodidacta Josep María Sirvent nacido en Girona en 1957. La obra tiene forma de un marco a través del cual se aprecia el paisaje del Cerro de la Silla. La obra Mirada tiene la particularidad de sustentarse solamente sobre uno de sus ángulos. El escultor señala en entrevista ${ }^{1}$ que se trata de una obra que siempre pretendió una directa interacción con el ciudadano. Sirvent habla de dos tipos de retos para definir la colocación de la escultura Mirada: el movimiento continuo por la parte de los espectadores que transitan en carro; y, por otro lado, otro tipo de movimiento que es mucho más leve, que es el de las personas que van en bicicleta, o de las personas que pudieran pasear por el entonces Parque lineal del río Santa Catarina. A partir de esos retos, cuenta el escultor, planeó realizar una escultura lo más sencilla posible, y que por otra parte, los dos tipos de espectadores, el de "mirada leve" y el de "mirada rápida", tuvieran un perspectiva ágil de lo que es una escultura, y que además lograra una relación con la pieza, de tal modo que cada espectador obtuviera su particular visión del espacio, su personal visión de la relación que tiene la escultura con la ciudad y consigo mismo, y que eso además provocara algún tipo de sentimiento.

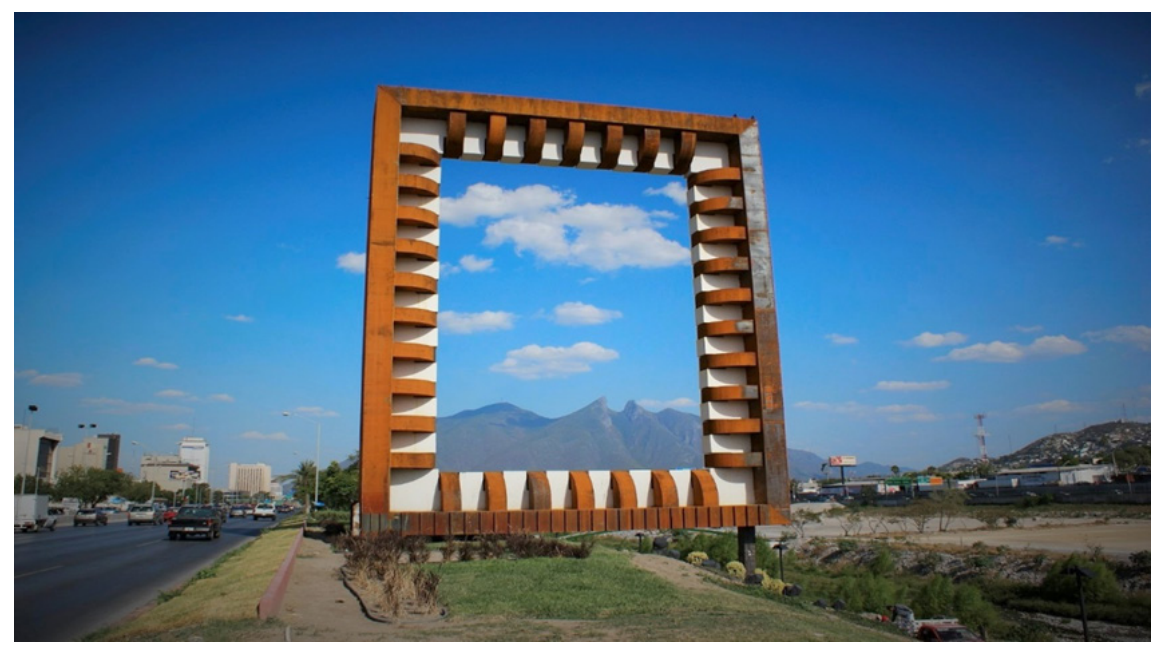

Título: Mirada
Autor: Josep María Sirvent
Técnica Acero
Dimensión: 26 metros de altura y 20 de ancho
Peso:150 toneladas
Año: 2009
Ubicación: Avenida Constitución y Serafín Peña
Foto: Guadalupe Mauricio H.
Monterrey, N.L., agosto 2009


El segundo caso es Albert Raymond Paley, escultor estadunidense nacido en Filadelfia, Pennsylvania (1944), cuyas esculturas se distinguen por el uso de colores primarios en la producción de su obra pública. Para el artista, sentir el lugar es fundamental en su obra y de esta vivencia surge, según explica², el color de la escultura que transmitirá un mensaje o carga emotiva, un sentir en el espacio que crea la escultura. La principal característica de Evanescencia es su llamativo color amarillo primario y su particular forma. Por su color y tamaño, la escultura interviene el paisaje hacia el poniente, generando una imagen asociada al cerro popularmente conocido como "las tres M", y al oriente con el Horno 3 de la extinta Fundidora y el Cerro de la Silla. ¿Cuál sería la mirada de Paley para la ciudad de Monterrey al elegir el color amarillo? En el Washington Post (2009) ${ }^{3}$, se refieren a "Evanesce", ubicada en Monterrey, como una obra que está luchando por ordenar el espacio: dominar la avenida, llamar la atención sobre un espacio desalentador, de cemento, ruido y tráfico; un parche en tierra baldía.

"Evanesce, a 2009 explosion of steel along a highway in Monterrey, Mexico, feels almost in argument with its patch of the urban wasteland. At the least, it is struggling to command the space, dominate the highway and draw attention away from the dispiriting ribbon of concrete, noise and traffic."

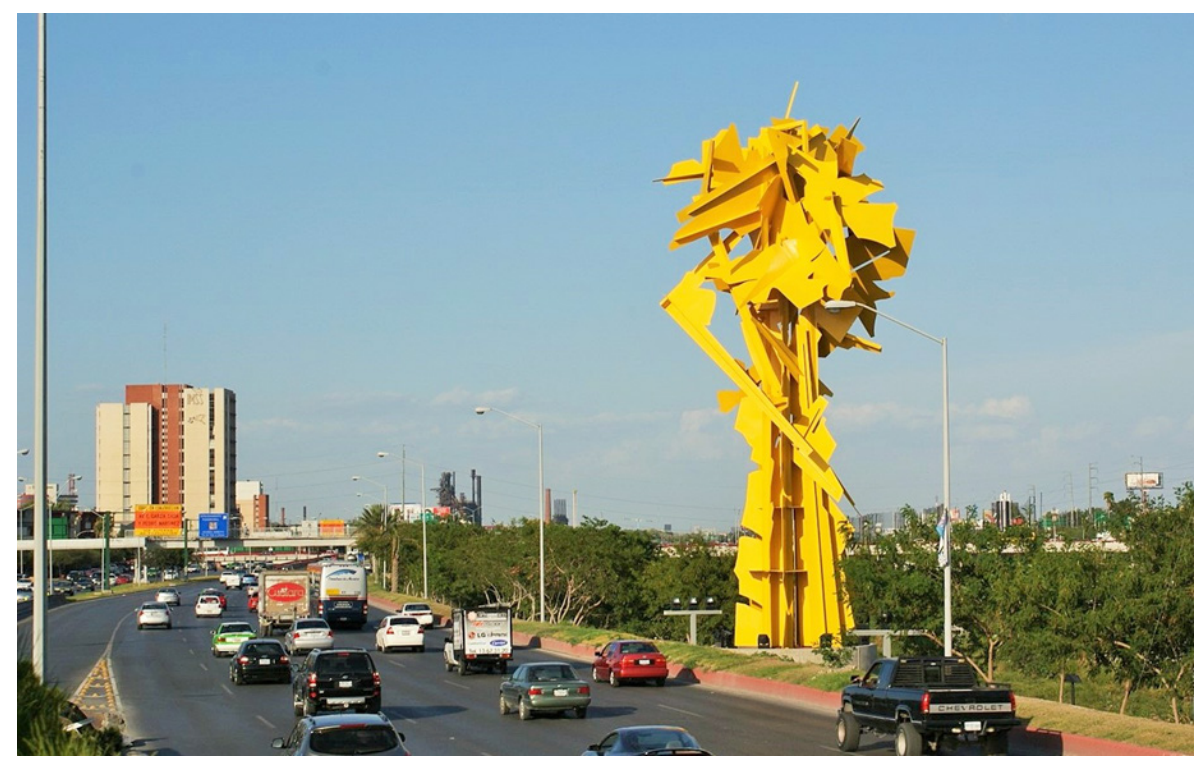

Título: Evanescencia

Autor: Albert Paley

Materiales de construcción: Concreto AC1 301 -2005

Acero Estructural AISC 1985

Dimensión: 5 metros de ancho y 20 de altura

Año de realización: 2009

Ubicación actual: Ciudad de Monterey, N.L., México.

Avenida Constitución a la altura de los terrenos del Parque

Fundidora II

Foto: Guadalupe Mauricio H. Monterrey, N.L., agosto 2009 


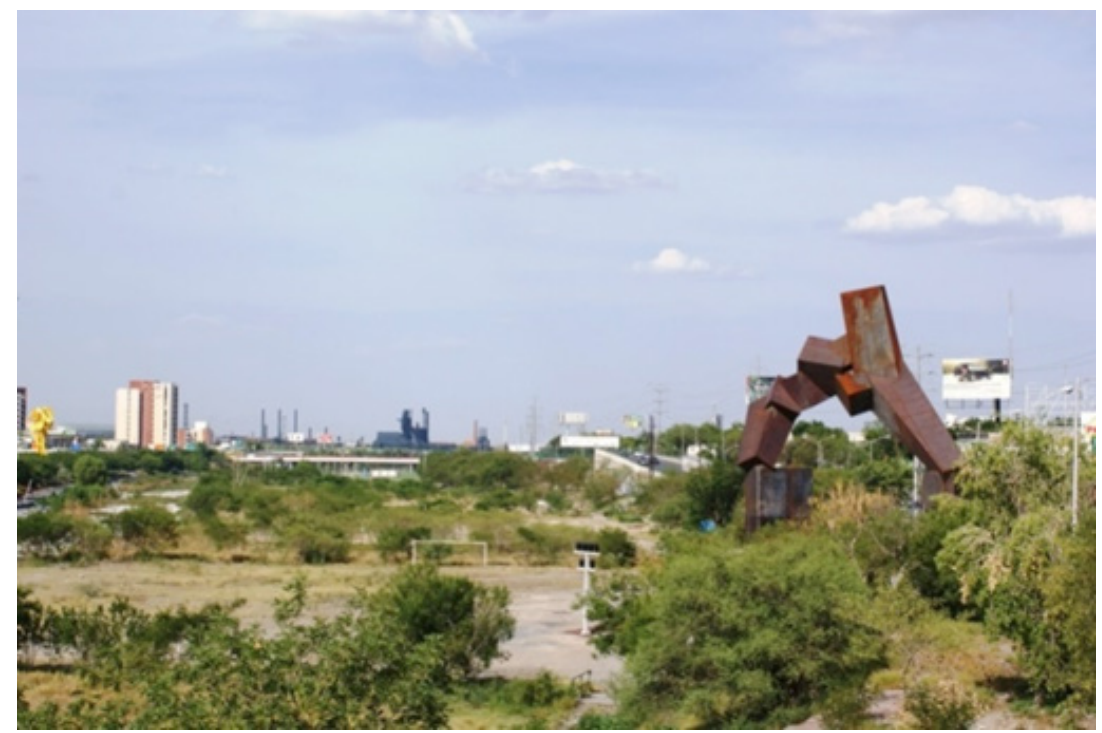

Título: Destino

Autor: Bruce Beasley

Materiales de construcción: Acero Estructural AISC 1985.

Concreto $\mathrm{ACl}$ 301-2005

Dimensión: Peso: 20 metros de altitud

Año de realización: 2009

Ubicación actual: Ciudad de Monterrey, N.L., México.

Avenida Morones Prieto, a la altura de las calles Ayutla y León Guzmán, frente al edificio CNIC

Foto: Guadalupe Mauricio H. Monterrey, N.L., agosto 2009

Destino, realizada por Bruce Beasley, nacido en 1939, Los Ángeles, está situada en Morones Prieto, a la altura de la entrada a la Colonia Nuevo Repueblo. Beasley expresó ${ }^{4}$ que una de sus ideas era fundir la escultura con el paisaje, tal y como a lo lejos se funden las estructuras de los hornos de la Fundidora con el entorno de Monterrey. La oxidación de la obra es una característica estética intencionada. La idea del autor es que la obra se sume al conjunto silvestre de un paisaje de vegetación seca como Destino. 

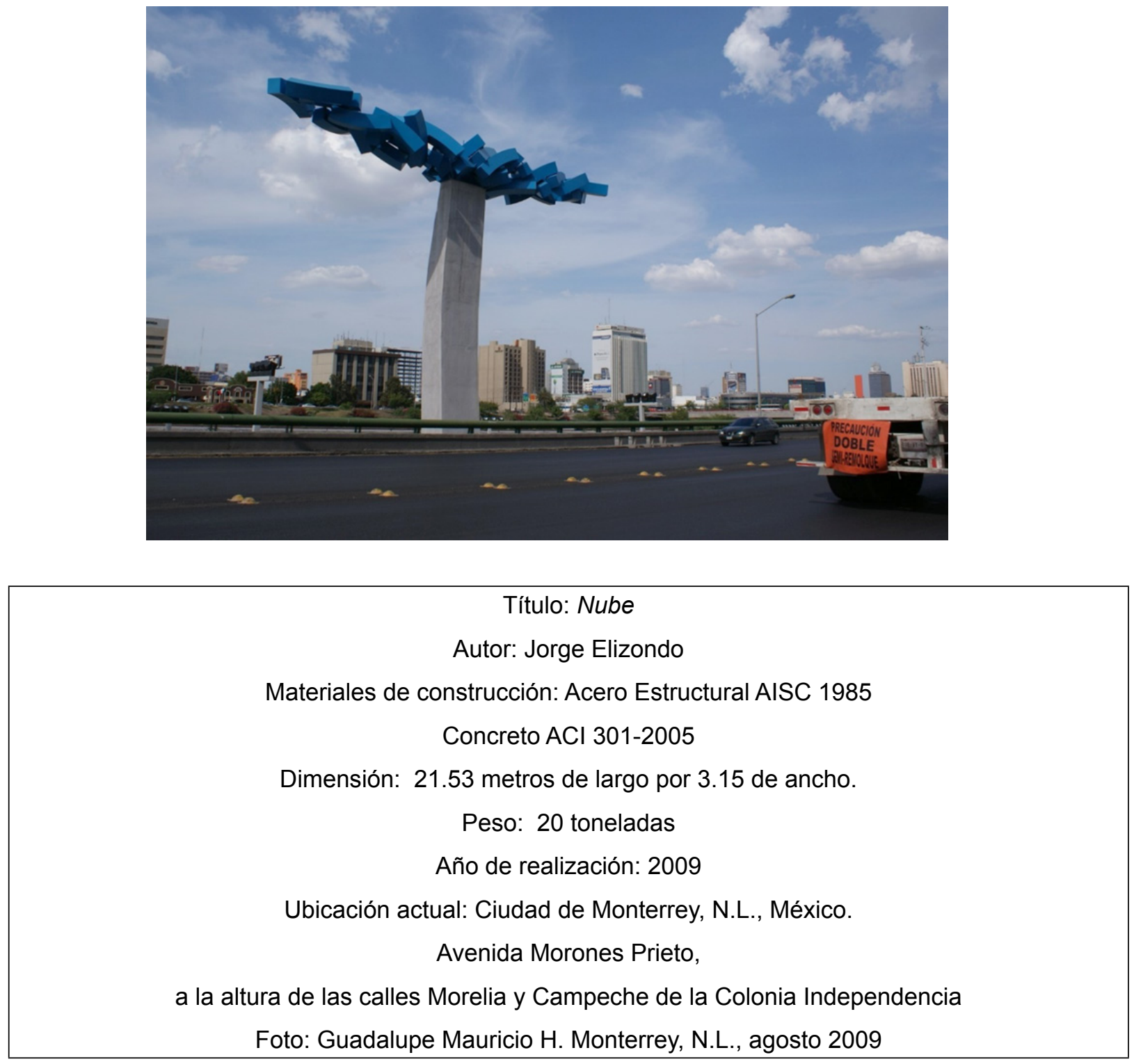

Nube es la escultura seleccionada mediante un concurso realizado por el gobierno de Nuevo León para que un artista local formara parte de la llamada Ruta Escultórica del Acero y el Cemento. Es de las pocas obras de la REAC que el escultor pudo realizar en su parte ingenieril. Elizondo en ocasión de la inauguración de la Ruta manifestó que la REAC forma parte de los trazos que hablan de "lo que nos inquieta, de dónde están nuestros anhelos, de dónde están nuestros miedos y la Ruta, y otras expresiones culturales que se están dando en la ciudad"5. 

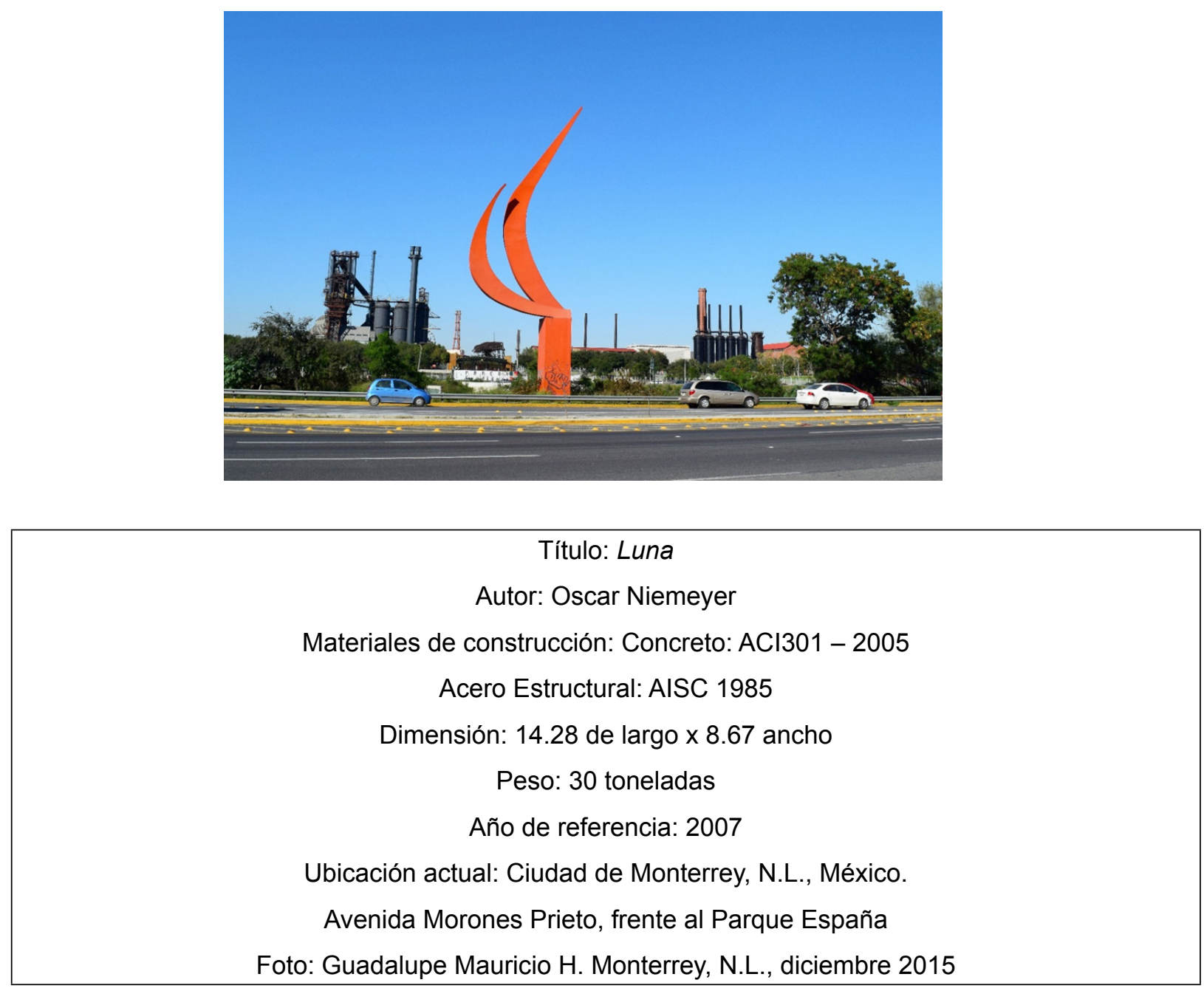

Luna fue la primera escultura de la Ruta en ser inaugurada, además de significar a la luna en su forma figurativa, tiene también forma de hoz, símbolo para representar a la clase campesina en el logotipo que identifica al partido comunista. Luna está ubicada por la avenida Morones frente a los Hornos 1 y 3 de la Fundidora, el lugar de trabajo de la mayor fuerza obrera de la ciudad Monterrey antes de 1985. 


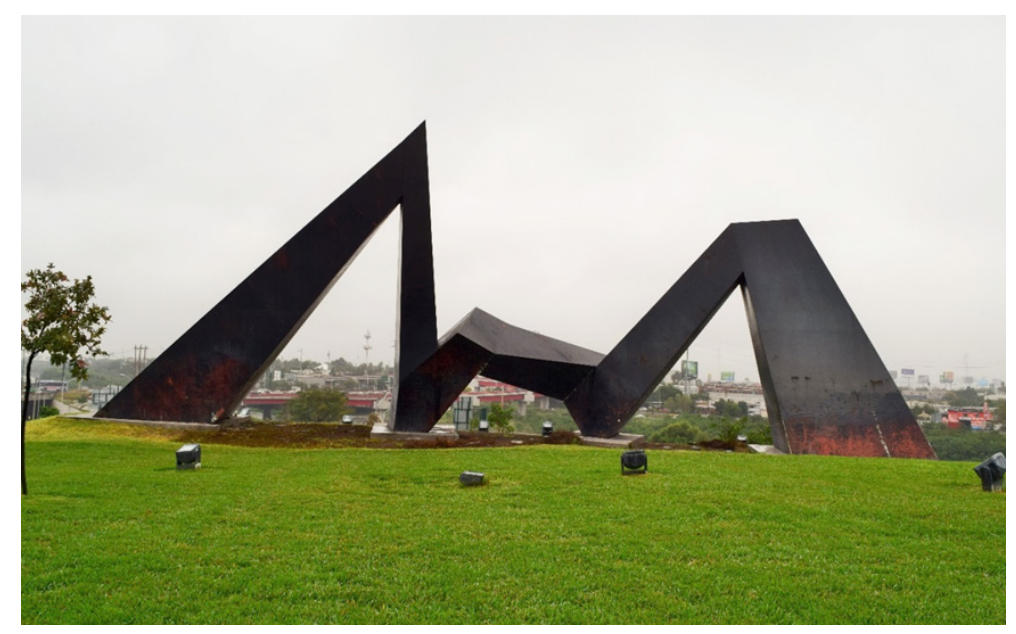

Título: El eco de la serpiente I

Autor: Mathias Goeritz

Materiales de construcción: Concreto: ACI $301-2005$

Acero Estructural: AISC 1985

Dimensión: 30 metros de ancho y 15 metros de altura

Año de realización: 2007

Ubicación actual: Ciudad de Monterrey, N.L., México.

Avenida Constitución, frente al Parque Fundidora de Monterrey

Foto: Guadalupe Mauricio H. Monterrey, N.L., noviembre 2015

El eco de la serpiente l es considerada la primera escultura de formato monumental de la carrera de Goeritz, fue elaborada originalmente para el patio del Museo Experimental EL ECO. Lejos de la concepción de Goeritz sobre la escultura como una obra que debía ser físicamente interactiva ${ }^{6}$, El Eco de la serpiente I se encuentra instalada en un montículo alejado de la interacción física de sus espectadores. Sin embargo, visualmente se incorpora al paisaje e incorpora al imaginario popular como "la escultura de los cerros" o en la "M de Monterrey". 


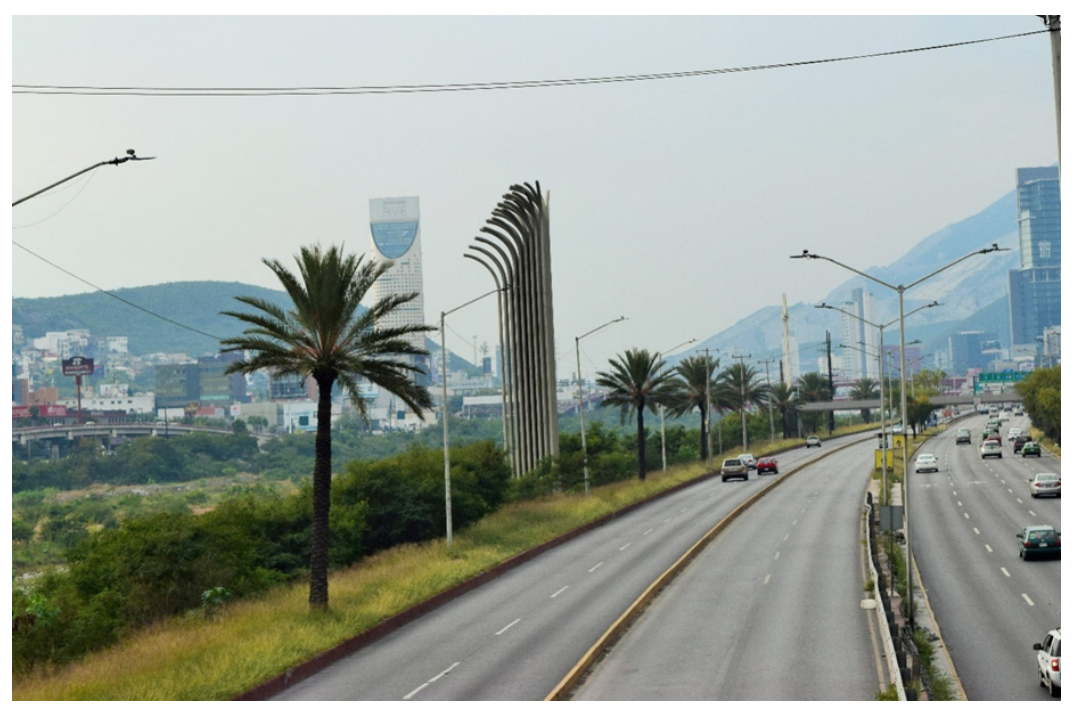

Título: Torsión 4

Autor: Julio Le Parc

Materiales de construcción: Acero Estructural AISC 1985

Concreto AC1301 - 2005

Dimensión: 20 metros de altura $\times$ 2,5 metros de radio

Año de realización: 2009

Ubicación actual: Ciudad de Monterrey, N.L., México.

Avenida Constitución, a la altura de las calles Lisboa y Mirador

Foto: Guadalupe Mauricio H. Monterrey, N. L., diciembre, 2015

Torsión 4 es la obra del artista argentino Julio Le Parc, nacido en Mendoza, Argentina (1928). La obra pesa 70 toneladas y está formada como una columna integrada por 42 tubos de acero, que se doblan en la parte superior hacia afuera, formando un triángulo, se encuentra frente a un área de restaurantes por la avenida Constitución. La escultura tiene la peculiaridad de ser una obra iluminada en sí misma y semeja un chorro de agua elevándose. 

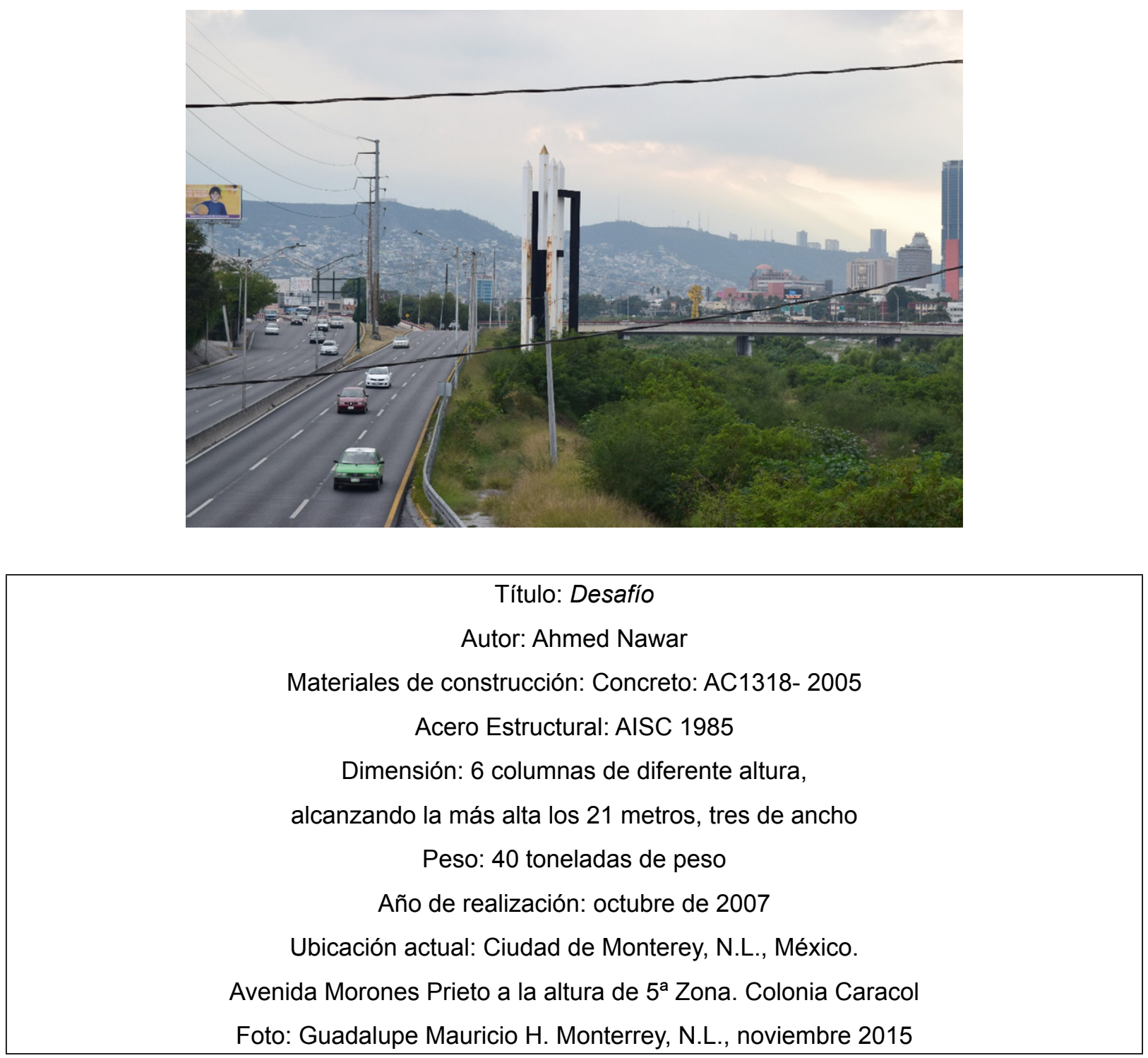

Desafío es la escultura del egipcio Ahmed Nawar formada por 16 columnas de diferente altura, alcanzando la más alta los 22 metros. Desafío tiene como fondo, uno de los nodos vehiculares más importantes y tradicionales que conectan a la ciudad con el norte y el sur, la avenida Garza Sada en conexión con la avenida Félix U. Gómez, pasando por Morones Prieto. La característica principal de la escultura es el conjunto de líneas o columnas en blanco y negro que juntas toman la fuerza de un monolito que apuntan hacia arriba desafiando el espacio que lo rodea. También simulan una gran urbe erizada de esbeltos rascacielos blancos y negros, similares a los de una realidad virtual. Al acercarse a la escultura entras a una de sus calles virtuales. 


\section{Características, obstáculos y observaciones en torno a la Ruta Escultórica del Acero y el Cemento}

Dentro de las observaciones críticas y estéticas sobre la REAC podemos decir, en tanto arte público, crea un nuevo espacio urbano que tiene como característica fundamental que es visual, no físico, donde predomina la función estética, no funcional y en gran medida tampoco es figurativo, que abre las posibilidades a diversas interpretaciones y experiencias individuales no excluyentes. Otra característica apunta a la modificación del rol del espectador, que pasa, o tiene la posibilidad de pasar, de un rol pasivo (mero receptor) a uno activo, en tanto creador de significados a partir de su propia experiencia vivida al interactuar con la obra artística sin mediaciones de los expertos o instituciones culturales.

Las esculturas, en tanto obras de arte, están hechas y ubicadas para mirarse a cierta distancia y velocidad. Consecuencia de estas condiciones, es que el contacto de las miradas dura generalmente unos segundos, alrededor de cinco o seis, a una velocidad de 80 kilómetros por hora. Sin embargo, la mirada tiene la posibilidad de rehacer el contacto con las esculturas en otro momento, otro día, aunque con cambios en la mirada y otras condiciones de visibilidad y climáticas. La mirada no se repite de forma idéntica, en todo caso se rehace o reconstruye en parte, al igual que el propio espacio visual.

Bajo las condiciones de distancia y velocidad, las esculturas están ahí, en un espacio público, al aire libre bajo las condiciones que impone el clima, para ser vistas desde distintas perspectivas, es decir, a partir del movimiento de la mirada, lo cual produce que las esculturas cambien, no sean iguales a pesar de ser las mismas. Ciertos elementos estéticos de las esculturas adquieren mayor importancia o se combinan de distinta manera entre sí, transformando la forma y significados, surgiendo variantes. En este sentido, las esculturas no tienen una sola manera de mirarse, ni estéticamente, ni espacialmente.

La mirada no se realiza en un solo sentido. La interacción se desarrolla de distintas formas, niveles y percepciones. Una prueba de lo anterior es que algunas esculturas son, por decirlo así, incorporadas por la mirada a la vida cotidiana a través de un mecanismo de selección de algunos elementos de la obra de arte: El Eco de la Serpiente I de Goeritz aparece en los diálogos cotidianos como la "escultura de los Cerros o de la M (Monterrey)". Este proceso de interacción y formación de un imaginario colectivo está en constante proceso.

El surgimiento de un nuevo espacio urbano visual, posmoderno, con base a la REAC, enfrenta varios obstáculos para su desarrollo y consolidación: el primero, y más importante, es el hecho de que las esculturas, no obstante su carácter fundamentalmente estético, sean parte de un proyecto que nace con el objetivo de mantener y fortalecer un relato de la ciudad industrial, fuertemente ideológico, como es la identificación de la grandeza de Monterrey con la visión de una élite empresarial local, que ha perdido significado y fuerza en la cultura global de las nuevas generaciones. El segundo obstáculo, tiene que ver con la concepción pragmática, utilitaria, de la cultura y el arte, que mantiene la clase política gobernante local. La consecuencia visible de esta concepción es la pérdida de interés en el arte si no es útil de manera inmediata o mediata a sus intereses políticos coyunturales. 
Un tercer obstáculo sería el hecho de utilizar el río Santa Catarina, el lecho y sus bordes, para construir o colocar obras, sin contar con la fuerza de la naturaleza, que históricamente ha reclamado el río como cauce natural. El huracán Alex arrasó el Parque Lineal y estuvo a punto de derribar y arrastrar las esculturas colocadas al borde del río.

\section{Conclusiones}

Con la REAC observamos la formación de un nuevo espacio urbano visual, performativo, que está rehaciéndose constantemente, en construcción permanente, con los elementos estéticos que ofrecen las esculturas a las miradas, pero también con la paulatina incorporación e interacción de las esculturas con el paisaje urbano.

Se enriquece el concepto de espacio público urbano con relación al arte público, dando cuenta de los nuevos rasgos que han surgido en el contexto de la globalización.

Se propone la Mirada como herramienta de los estudios visuales para el análisis de los nuevos fenómenos urbanos.

Así mismo, se vislumbra una nueva fundación de Monterrey como ciudad posmoderna, una ciudad invisible en la cual las esculturas se consideran las marcas o señales.

Se establece que la REAC representa un antecedente importante que se debe revisar, como modelo basado en el arte público para impactar la ciudad. El proyecto basado en la donación por parte de los artistas abre una gama de oportunidades que existen para trasformar la ciudad, su espacio público y el arte.

\section{Referencias}

- Amendola, G. (2000). La Ciudad Postmoderna. Magia y Miedo de la Metrópolis Contemporánea. Madrid: Celeste.

- $\quad$ Berger, J. (2010). Modos de Ver. Barcelona: Gustavo Gili.

- $\quad$ Borja, J \& Muxi, Z. (2003). El espacio público, ciudad y ciudadanía. Barcelona: Electa.

- Brea, J. L. (2005). Estudios visuales. La epistemología de la visualidad en la era de la globalización. Madrid: Akal.

- $\quad$ Castells, M. (2008). La cuestión urbana (17 ed.). México: Siglo XXI.

- $\quad$ Debray, R. (1994). Vida y Muerte de la imagen, Historia de la mirada en Occidente. Barcelona: Paidós

- $\quad$ Delgado, M. (2007). Sociedades movedizas. Barcelona: Anagrama.

- Grau, M. (2007, septiembre). El arte público en la posmodernidad. Kitsch, ironía e interacción con el ciudadano. Asociación Aragonesa de Críticos de Arte. En: http://www.aacadigital.com/contenido.php?idartículo=20.

- Mauricio, G. (2016). Arte y espacio públicos, un discurso de lo urbano. Monterrey: el caso de la Ruta Escultórica del Acero y el Cemento (Tesis Doctoral, Universidad Autónoma de Nuevo León, Facultad de Arquitectura, Programa de Doctorado en Filosofía con orientación en Arquitectura y Asuntos urbanos. Documento no publicado). 
- $\quad$ Ortiz, I. (2009). La estética, los escenarios, los dones y los engarces de lata. El edificio corporativo del grupo ALFA en Monterrey, Manuscrito no publicado. Aspirante al Premio de Investigación Histórica Israel Cavazos Garza. Monterrey, N. L.

- $\quad$ Pallasmaa, J. (2006). Los ojos de la piel. La arquitectura y los sentidos. Barcelona: Gustavo Gili.

- $\quad$ Pérez, V. (2007, julio-septiembre). Ruta del Acero y del Cemento. Identidad cultural que revela un sentido de permanencia. Rizoma, 05. Pp. 42.44. En http://es.scribd.com/document/6851045/Rizoma-5-Julio-Septiembre-200

- Valdez, A. (2007, julio-septiembre). PARQUE LINEAL RÍO SANTA CATARINA. Un esfuerzo sustentable de gran impacto en la imagen urbana Rizoma, 05. Pp. 38.41. En: https://es.scribd.com/document/6851045/Rizoma-5-JulioSeptiembre-2007

\section{Notas}

1 Mauricio, G. (2009, septiembre 18). Entrevista a Sirvent [Audio] En Coloquio sobre escultura urbana y espacio público. Agencia para la Planeación del Desarrollo Urbano de Nuevo León.

2 Paley Studios (2016). Public Arte Process [video]. En: http://www.albertpaley.com/index.cfm?Page=Public Art Process

3 Kennicott, P. (July 2, 2014). Albert Paley's fluid, yet sci-fi metal works at the Corcoran. The Washington post: Washington, D. C. En: http://www.washingtonpost.com/entertainment/museums/albert-paleys-fluid-yet-sci-fi-metalworks-at-the-corcoran/2014/07/02/5f6f7f68-fe2e-11e3-932c-0a55b81f48ce_story.html

4 Mauricio, G. (2009, septiembre 18). Grabación de audio del Coloquio sobre escultura urbana y espacio público. Agencia para la Planeación del Desarrollo Urbano de Nuevo León.

5 Mauricio, G. (2009, septiembre 18). Grabación de audio del Coloquio sobre escultura urbana y espacio público. Agencia para la Planeación del Desarrollo Urbano de Nuevo León.

6 Ver Garza, D. (2012). Mathias Goeritz y la arquitectura emocional. Una revisión crítica (1952-1968), México: CONACULTA. 